\title{
Modelagem na Educação Matemática, das ideias às proposições oficiais
}

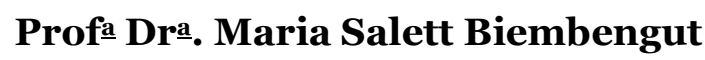

Organizadora deste número temático da revista "Com a palavra, o professor"

A Modelagem na Educação Matemática, nessas quatro décadas, tem sido crescente. Pesquisas mostram que estudantes, em qualquer fase de escolaridade, apresentam melhor desempenho matemático quando se faz uso da modelagem como método de ensino, em especial, na compreensão e na resolução de situações-problema de outra área do conhecimento em que eles apresentam interesses.

Como resultado natural, surge a literatura, de magnitude nacional e internacional e, por consequência, incorporada em documentos oficiais de Educação, como as Diretrizes Curriculares Nacionais que influenciam reformas curriculares e as Propostas Pedagógicas dos Estados. Documentos que contribuem para que livros didáticos apresentem situaçõesproblema e fenômenos da realidade, e Cursos de Formação de Professores de Matemática incluam à grade curricular disciplinas sobre Educação Matemática, em especial, a Modelagem.

Crescente, ainda, tem sido o número de preleções sobre pesquisas e/ou experiências em sala de aula nos eventos de Educação e de Modelagem na Educação em âmbitos regionais, estaduais, nacionais e internacionais. As preleções em eventos de Educação são fontes de recursos para a melhoria do ensino e da aprendizagem. Muitos professores se interessam em fazer uso da Modelagem em suas práticas pedagógicas devido a um contato primeiro com produções, ou atividades que incentivam a utilização. E, em um processo cíclico-crescente, aqueles que se motivam e efetuam algum tipo de atividade - seja como uma prática em sala de aula ou como pesquisa - avançam para melhor compreender os processos e resultados, esperam compartilhar em algum evento.

Desde as primeiras ideias e proposições dos precursores pela Modelagem na Educação brasileira nos anos de 1970, o número de adeptos avolumou-se, de tal forma que já não é possível saber quem são esses adeptos. Este próspero interesse pela Modelagem é, sem dúvida, resultante da ação de alguns professores e seus respectivos estudantes que enveredaram pela proposta. Proposta, cuja semente advém das proposições dos precursores, faz-se presente em documentos educacionais oficiais e, ainda, amplia de forma significativa as pesquisas, as produções acadêmicas, os documentos. Amplia-se de tal forma que nem sempre nos damos conta dos começos: quem foram os precursores, quais foram suas propostas, ou mesmo: Como ações e propostas individuais de Modelagem na Educação tornam-se 
manifestação, revelam elementos, fornecem um quadro de referências das experiências realizadas, e ainda levam a uma rede de conhecimento?

A resposta a essa questão pode ser obtida 'especialmente' a cada leitor dessa Edição da Revista Com a Palavra o Professor - edição especial sobre o tema Modelagem Matemática na Educação. Para dispor dessa edição, na impossibilidade momentânea de obter a contribuição de todos os colegas adeptos a Modelagem na Educação, elegi aqueles cujas produções eu tenho me inteirado com mais frequência. Assim, o que almejo - nesta Edição Especial - é trazer a todos que se interessam pela Modelagem na Educação, as contribuições de colegas - adeptos da Modelagem - suas proposições, seus entendimentos, suas ideias.

Vale sublinhar que 'passei muito tempo' tentando eleger uma ordem. E por não conseguir, arrisco e 'já aceito as críticas'. Portanto, em um processo natural de autodefesa, afirmo que esta ordem dos artigos se trata de uma das tantas possíveis 'leituras e interpretações' dos respectivos escritos, portanto, tal ordem 'traduz' o que cada artigo, sob meu olhar, meu entender, meu sentir me revela, me orienta, me encaminha.

É importante sublinhar, que o artigo de autoria da Lilian em parceria com o Wellinton eu constei como último, pois eles trazem uma identificação e respectiva classificação dos núcleos temáticos da pesquisa em Modelagem apresentados em um dos SIPEM - o sétimo. Portanto, o artigo deles contribui aos leitores terem uma 'noção' do alcance da Modelagem na Educação desde que os precursores, como por exemplo, o professor Aristides Camargos Barreto passou a fazer uso em seu ensino de Cálculo (CDI) nos anos de 1970.

Minha expectativa é que cada um desses artigos contribua aos que se interessem pela Modelagem na Educação Matemática a enveredarem pelos 'movimentos da Modelagem na Educação - seja na Educação Matemática, na Educação das Ciências da Natureza, das Sociais, das Artísticas ' e, assim, semear, deixar marcas, assinalar caminhos.

Dos artigos:

1) Modelagem Matemática: O desafio de se ‘fazer’ a Matemática da Necessidade..., o autor João Frederico Meyer apresenta a Modelagem como um instrumento fundamental de trabalho, por um acadêmico em Matemática Aplicada para quem a Modelagem Matemática tem seus aspectos fundamentais. $\mathrm{O}$ autor consta uma sequência de ações no ato de se modelar uma situação-problema, criando certa categorização. Na sequência, a partir das etapas no Modelar as situações-problema, diversos aspectos apresentados que suscitam a necessidade de se utilizar conceitos matemáticos na solução da situação-problema - o que requer um estudo dessas situação à sua Modelagem crítica, aos processos de avaliação de resultados e sua aplicação a problemas da vida real.

2)Modelagem Matemática e Educação Ambiental no Contexto da Cultura Digital, os autores Arlindo José de Souza Jr e Deive Barbosa Alves trazem resultados da 'educação ambiental' na preservação d'água realizados por um grupo de estudantes do $2^{0}$ 
ano do Curso Técnico de Meio Ambiente, integrado ao Ensino Médio Regular, de uma escola da Rede Federal de Uberlândia (MG). O objetivo principal dessa atividade experimental foi incentivar os estudantes a produzir Ciência e Tecnologia na elaboração de protótipos digitais. A partir da questão-guia - Como a produção de uma tecnologia (descarga digital) possibilita a economia de água, utilizada no vaso sanitário de nossas residências? - os estudantes: $\left(1^{\circ}\right)$ buscaram informações sobre os dispositivos utilizados em um modelo comum de banheiro; e $\left(2^{\circ}\right)$ confeccionaram um protótipo com componentes digitais no controle do volume na saída d'água. A pesquisa permitiu aos autores, além dos benefícios à preservação dos recursos naturais, compreender a constituição da modelagem matemática vinculada a 'cultura digital' na apropriação desses conhecimentos escolares.

3) Modelagem Matemática com Produção de Vídeos Digitais: Reflexões a Partir de um Estudo Exploratório os autores Marcelo de Carvalho Borba e Neil da Rocha Canedo Junior, traz suas reflexões de um estudo exploratório por eles realizado que integra 'modelagem \& produção de vídeos digitais em Educação Matemática'. Eles desenvolveram atividades com estudantes, na qual uma atividade de Modelagem é realizada e apresentada por meio de um vídeo digital produzido por esses estudantes. Sob o apoio da teoria que trata dos 'seres-humanos-com-mídias' e da 'semiótica social', os autores refletiram e conjeturaram sobre as 'possibilidades' que este processo pedagógico traz a cada um dos estudantes.

4) A Abordagem de Conteúdos de Matemática em Práticas de Modelagem e as Implicações para o Currículo, a autora Regina Helena de Oliveira Lino Franchi apresenta suas reflexões sobre a abordagem de conteúdos de Matemática em práticas de Modelagem realizadas com estudantes de Licenciatura em Matemática e Química e, ainda, consta a relação destas práticas com os programas curriculares. Na análise a autora mostra evidências dessa abordagem contextualizada, como também, a adoção de formas flexíveis e não lineares da organização curricular.

5) Estratégias Heurísticas como Meios de Ação em Atividades de Modelagem Matemática, a autora Lourdes Maria Werle de Almeida apresenta suas reflexões em relação as 'estratégias' heurísticas utilizadas pelos estudantes do Curso de Licenciatura ao resolverem situações-problema em atividades de Modelagem. O processo analítico adotado pelos estudantes na resolução do problema sugere que permitiu a eles a desenvolver suas respectivas atividades - propiciando-lhes 'descobrir' - 'heureca'.

6) Modelagem Matemática e Big Data no Desenvolvimento da Literacia Digital os autores Rose G. Gayeski, Rodrigo D. Vecchia e Marcus V. Maltempi trazem o assunto Big Data que permite cruzar dados, informações e até soluções. Essa 'fonte de dados' permite interpretações diversas e, portanto, soluções e/ou criações de outras objetos, outras informações, outras teorias. Como a modelagem está no âmago das resoluções ou mesmo 
das criações, os autores consideram o Big Data aliado aos recursos disponíveis do Google (pelos diversos 'instrumentos) meios para estimular o interesse dos estudantes do Ensino Médio no desenvolvimento da Literacia Digital.

7) Etnomodelagem como Movimento de Glocalização nos Contextos da Etnomatemática e da Modelagem, os autores Milton Rosa e Daniel Clark Orey expressam suas reflexões sobre o 'conhecimento', sob dois aspectos: local e glocal. O local se expressa a partir dos dizeres, dos contares sobre ideias e práticas no/do estar, fazer, propor; e o glocal, conduz aos 'saberes', instigando saber dos saberes, ultrapassando o 'entendimento' do comum. Nesse entendimento, os saberes expõem-se, o que inclui a matemática. Os autores finalizam o texto confirmando que a Etnomodelagem neste 'processo glocalizante' propicia outros entendimentos, outras compreensões dos 'fazeres' das pessoas em seus contextos.

8) Um olhar aos Núcleos Temáticos em Modelagem Matemática Emergidos das Produções do VII SIPEM, os autores Lilian A. Kato e Wellington P. Oliveira tratam das pesquisas brasileiras em Modelagem na Educação a partir de um conjunto de produções de Modelagem Matemática apresentadas no VII SIPEM, na expectativa de identificar os núcleos temáticos de pesquisa em Modelagem Matemática emergem dessas produções. Eles analisaram respectivos artigos publicados pelo Grupo de Trabalho 10 na VII edição do SIPEM. Os autores identificaram tendências temáticas e respectivos avanços em relação à formação inicial de professores, embora eles suponham que haja um 'movimento convergente' sobre temas interligados à Modelagem como prática e pesquisa no Brasil e outros países. 